\title{
Dietary Lipid and Postnatal Development. I. A Model for Neonatal Studies Requiring High and Low Fat Diets from Birth
}

\author{
JUNE R. APRILLE(18) AND JILL RULFS \\ Children's Service, Massachusetts General Hospital; Department of Pediatrics, Harvard Medical School; \\ Shriner's Burns Institute, Boston, Massachusetts, USA
}

\section{Extract}

As a prerequisite to a biochemical investigation into the role of dietary lipids in regulating perinatal fatty acid metabolism, we developed and evaluated a model in which the amount of lipid in the diet can be easily controlled from birth to at least 10 days of age. Neonatal rabbits were fed purified equicaloric diets in which lipid supplied either $14.2 \%$ or $77.6 \%$ of the total calories. Mortality due to all causes was about $40 \%$ in both groups. Some differences in physical development between the two groups were noted. Animals receiving the smaller amount of lipid (LF group) gained weight to $150 \%$ birth weight by day 10 , whereas the group receiving the larger amount of lipid (HF group) did not gain. In addition, the HF group had lower body temperatures, smaller liver and kidney weights, and greater brain weights relative to body weight. These differences are discussed in relation to the composition of the HF and LF diets. The model promises to provide a direct approach to a more precise evaluation of varied dietary regimens in the neonatal period. In particular, the model lends itself to studies relating diet to developing biochemical functions. In an accompanying paper, we report the results of an investigation comparing fatty acid oxidation in heart and liver of neonates fed the HF and LF diets described here.

\section{Speculation}

The model described here overcomes many of the difficulties associated with maintaining neonates on artificial diets in a way that allows precise control of diet composition and environment for at least the first 10 postnatal days. This should provide a new approach to many old questions regarding the specific role of lipids and other dietary constituents in modulating biochemical development.

The sequence of nutritional events accompanying parturition and early postnatal life is dramatic. The abrupt withdrawal of substrates supplied via maternal circulation in utero is usually followed by a brief period of starvation; after this the neonate is suddenly presented with a milk diet rich in lipid. The change in availability of dietary lipid is suspected as having a role in modulating the activities of certain enzymatic pathways, particularly those involved in fatty acid synthesis $(4,12,14)$ and fatty acid oxidation $(1,13)$. This idea, and others which propose a specific role for lipids in development, could be tested directly if it were possible to vary the lipid fraction in the postnatal diet from the time of birth. Our prior experience suggested experimental designs such as this would be feasible using the artifically fed neonatal rabbit (3). The rabbit model appears versatile enough to allow changes in the relative proportions of dietary constituents so as to provide equicaloric diets of varied composition. As a prerequisite to a biochemical investigation into the role of lipids in regulating perinatal fatty acid metabolism (2), we decided to evaluate several parameters of growth and development in neonates maintained on different diets in which the relative proportion of lipid was varied.

\section{METHODS}

\section{CARE AND FEEDING OF NEONATES}

New Zealand white rabbits were bred and parturition induced with oxytocin as described previously (3). Newborns were numbered, weighed, and immediately placed in a $30-33^{\circ}$ humidified incubator. Only animals over $40 \mathrm{~g}$ at birth were used. Neonates were distributed so as to provide approximate weight pairs between each of two groups. Groups were labeled low fat (LF) and high fat (HF) and were fed LF and HF artificial diets (see below), respectively. Diet was administered by once-daily tube feedings as previously described (3) and according to the following schedule. An amount of formula equivalent to $8 \%$ body weight was given on the day of birth, $10 \%$ on the next 2 days, $12 \%$ at 3 and 4 days, $15 \%$ at 5 and 6 days of age, and $17-20 \%$ on all subsequent days. Actual intake was measured by pre- and postfeeding weighings. Growth curves were plotted on the basis of weights before feeding each day.

\section{ARTIFICIAL DIETS}

HF animals were fed a diet high in lipid content; the LF group was fed an equicaloric diet low in lipid. Both diets were modified from the basic artificial diet previously described (3) so as to balance lipid calories in the HF diet with protein and carbohydrate calories in the LF diet. The composition of both diets is shown in Table 1. The use of an infant formula (15) to provide vitamins and minerals was arbitrary. In other studies (to be reported separately) we have used a simple vitamin diet fortification mixture (16) to avoid using prepared formula. The composition of the two diets used in this study is discussed further in Results.

\section{BODY TEMPERATURE}

Rectal temperature was measured daily using a microthermistor probe with input to a Yellow Springs Telethermometer.

\section{BLOOD URINARY NITROGEN (BUN) AND ORGAN WEIGHTS}

These were determined as previously described (3).

\section{RESULTS}

\section{ADEQUACY OF HF AND LF DIETS}

The immediate problem in establishing one diet low in lipid content for comparison with a diet high in lipid was a means of balancing the calories in the two mixtures. We had hoped to balance lipid calories against carbohydrates to minimize differ- 
ences in protein content in the two diets. However, normal rabbit milk has low carbohydrate ( $\sim 5 \%$ total calories), and very high lipid ( $\sim 57 \%$ total calories) and protein (38\% total calories) fractions (6). The amount of glucose, sucrose, or lactose required in a low fat diet to balance lipid calories in a high fat diet presented an intolerable osmotic load. Glucose polymers in the form of partially digested cornstarch (15) caused severe diarrhea. We therefore balanced lipid calories in the HF diet against increased protein and lactose calories in the LF diet. Protein loads in excess of $18 \mathrm{~g} / 100 \mathrm{~g}$ diet were also poorly tolerated. With these restrictions the final formulations of both diets were calorie deficient ( $\sim 67 \%$ normal milk) and the HF diet was also protein deficient (20\% normal milk). An estimated analysis of both diets is shown in Table 2. Our objective was achieved in that animals in the LF group received only $\sim 14 \%$ of total calories as lipid, whereas those in the $\mathrm{HF}$ group received $\sim 78 \%$ of total calories as lipid. Animals were maintained on either diet for as long as 10 days, with mortality rates of $\sim 40 \%$ in both groups.

\section{GROWTH AND DEVELOPMENT}

Both groups gained weight slowly but steadily to 3 days of age. On subsequent days the LF group gained rapidly, reaching $150 \%$ of birth weight by day 10, but the HF group did not gain at all (Fig. 1). Even though animals in the HF group did not gain weight, they were active, alert, and except for small size compared well to littermates in the LF group.

\section{BUN}

BUN values for animals maintained on the $L F$ diet averaged $62.5 \mathrm{mg} / 100 \mathrm{ml}$. BUN in the HF group averaged $18.0 \mathrm{mg} / 100 \mathrm{ml}$. BUN in nursing pups is about $25.2 \mathrm{mg} / 100 \mathrm{ml}$ (3).

Table 1. Composition of equicaloric low fat $(L F)$ and high fat (HF) artificial diets ${ }^{1}$

\begin{tabular}{lcc}
\hline \multicolumn{1}{c}{ Addition } & LF diet, $\mathrm{g}$ & HF diet, $\mathrm{g}$ \\
\hline Ovalbumin & 15 & 2 \\
Lactose & 5 & 0 \\
Peanut oil & 0 & 4 \\
Cottonseed oil & 0 & 4 \\
Formula CP 5332A & 50 & 50 \\
Water & 30 & 40 \\
CP 5332A (15) & &
\end{tabular}

${ }^{1}$ Fifty grams of infant formula CP 5332A supplies a vitamin-mineral supplement and approximately $1.8 \mathrm{~g}$ fat (soy, coconut, and corn oils), $1 \mathrm{~g}$ protein (soy protein), and $3.4 \mathrm{~g}$ carbohydrate (corn syrup solids). Other constituents are from commercial sources. For comparison, it should be noted that normal rabbit milk contains approximately $15.5 \mathrm{~g}$ protein, 10.5 g lipid, and $2.0 \mathrm{~g}$ carbohydrate/ $100 \mathrm{~g} \mathrm{(3).}$

Table 2. Approximate analysis of high fat $(H F)$ and low fat $(L F)$ diet estimated from constituents listed in Table $I^{1}$

\begin{tabular}{|c|c|c|c|c|c|c|}
\hline & \multicolumn{3}{|c|}{ LF diet } & \multicolumn{3}{|c|}{ HF diet } \\
\hline & $\begin{array}{c}\mathrm{g} / \\
100 \mathrm{~g}\end{array}$ & $\begin{array}{l}\mathrm{kcal} / \\
100 \mathrm{~g}\end{array}$ & $\begin{array}{c}\% \\
\text { Total } \\
\text { cal }\end{array}$ & $\begin{array}{c}\mathrm{g} / \\
100 \mathrm{~g}\end{array}$ & $\begin{array}{l}\mathrm{kcal} / \\
100 \mathrm{~g}\end{array}$ & $\begin{array}{c}\% \\
\text { Total } \\
\text { cal }\end{array}$ \\
\hline Protein & 16 & 69.1 & 56.9 & 3.0 & 13.0 & 10.7 \\
\hline Fat & 1.8 & 17.3 & 14.2 & 9.8 & 94.1 & 77.6 \\
\hline Carbohydrate & 8.4 & 35.1 & 28.9 & 3.4 & 14.2 & 11.7 \\
\hline Water & 73.8 & & & 83.8 & & \\
\hline Total calories & & 121.5 & & & 121.3 & \\
\hline
\end{tabular}

${ }^{1}$ Calories were calculated using standard gram-calorie equivalents for protein $(4.32 \mathrm{kcal})$, fat $(9.6 \mathrm{kcal})$, and carbohydrate $(4.18 \mathrm{kcal})$.

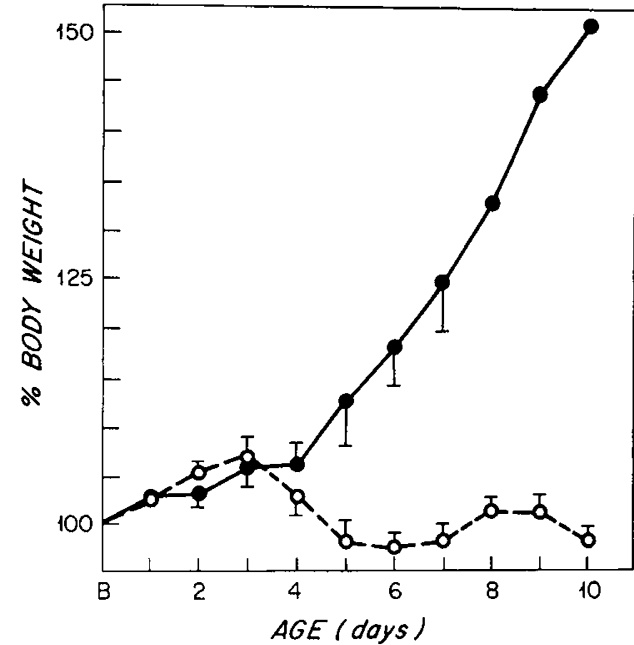

Fig. 1. Growth curves comparing weight gain of littermates fed equicaloric amounts of either a high fat (HF, O- - -O) or low fat (LF, - - diet as described in the text. Each point is an average for between 2 and 10 animals from several experiments. The bars indicate 1 SEM for each point when $n>2$. Birth weight averaged $53.3 \pm 2.36 \mathrm{~g}$ and $54.9 \pm$ $1.80 \mathrm{~g}$ for the HF and LF groups, respectively.

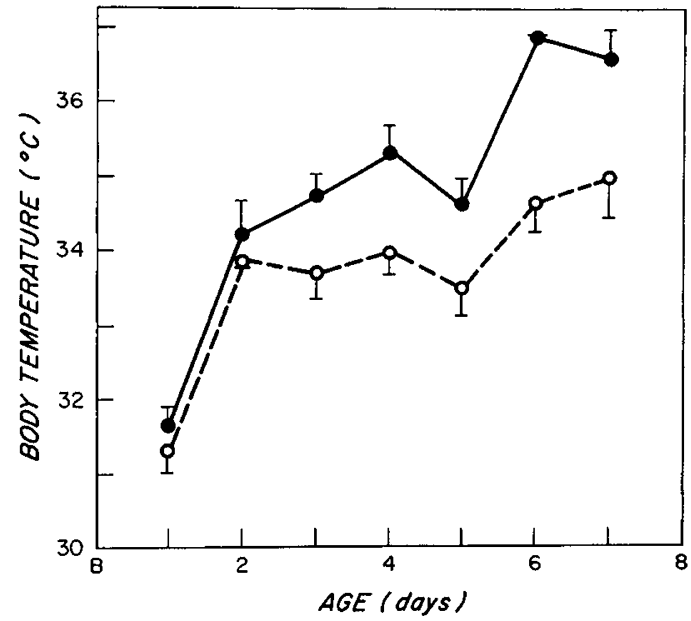

Fig. 2. Development of body temperature in littermates maintained on high fat $\left(\mathrm{O}-\mathrm{O}^{-}\right)$or low fat (-) diets as described in the text. Body temperatures (rectal) were taken daily. The data shown is from a typical experiment with three animals in each group. The bars indicate 1 SEM.

\section{BODY TEMPERATURE}

Rectal temperature in both HF and LF groups were monitored daily and are shown in Figure 2. Animals in the HF group had body temperatures consistently below littermates in the LF group after day 2. Body temperature development in the LF group was similar to the pattern observed for mother-fed animals (not shown).

\section{ORGAN DEVELOPMENT}

Organ weights normalized relative to body weight are shown as a function of age in Figures 3-7. In both the HF and LF groups, fastest relative growth occurred in the kidney (Fig. 3), followed by the brain (Fig. 4), skeletal muscle (Fig. 5), heart (Fig. 6), and liver (Fig. 7), respectively. In this respect, the pattern in both groups resembled the general one for normal mother-fed animals (3).

In comparing organ development in pups on HF vs. LF dietary regimens, no difference was observed for heart (Fig. 6) or skeletal muscle (Fig. 5); however, brain (Fig. 4) was consistently larger in 

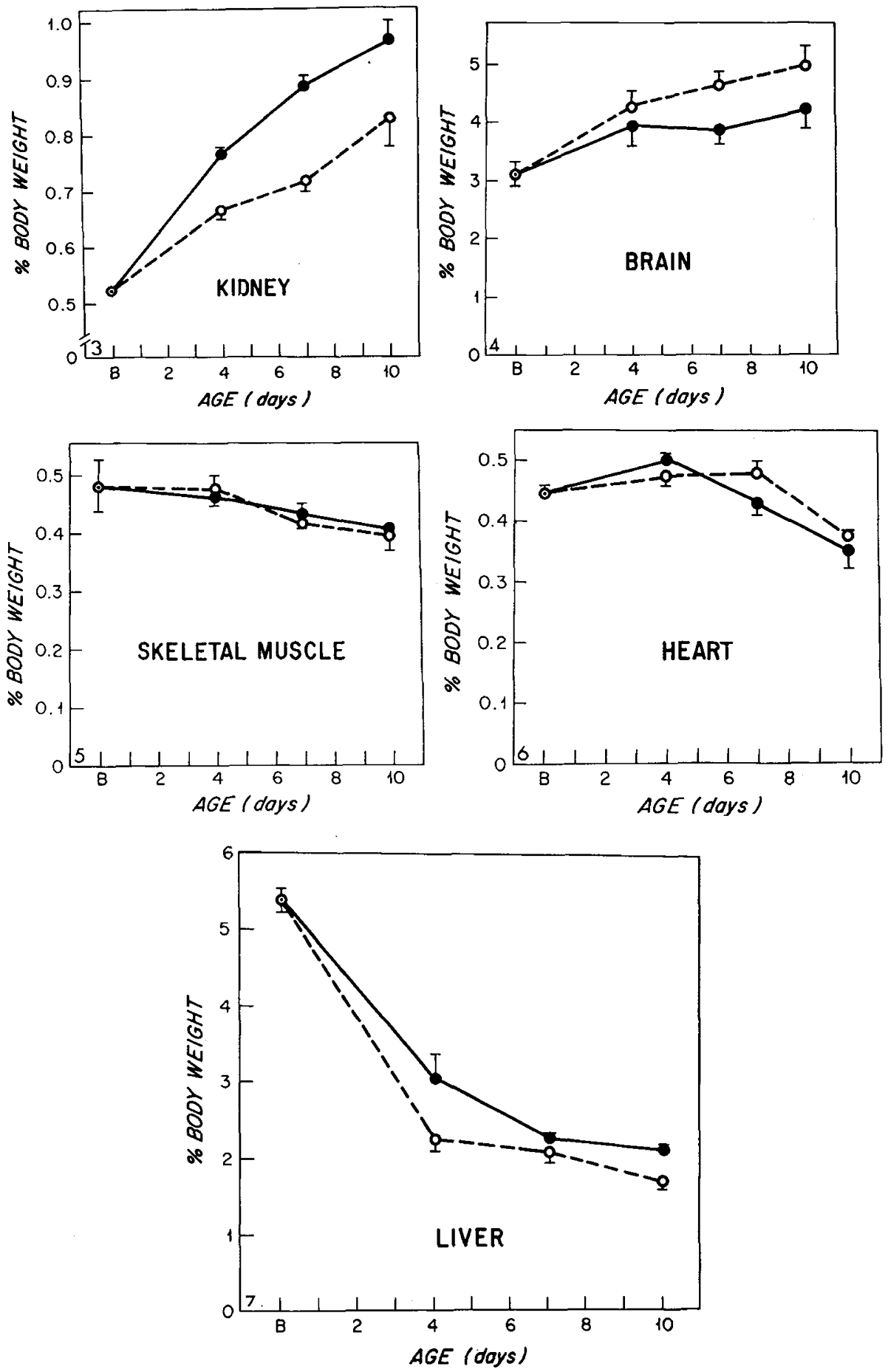

Figs. 3-7. Organ weights relative to body weights are shown as a function of age for littermates maintained on high fat $\left(\mathrm{O}_{---}-\mathrm{O}\right)$ or low fat ( diets as described in the text. Kidney, brain, skeletal muscle (gastrocnemius), heart (ventricles), and liver are shown in Figures 3-7, respectively. Each point is an average for between three and seven animals from several experiments. The bars indicate I SEM.

the HF group, whereas liver (Fig. 7) and kidney (Fig. 3) were smaller relative to body weight. The differences observed for liver and kidney were already apparent at 4 days of age before any difference in body weights was observed (see Fig. 1).

\section{DISCUSSION}

At birth there is a sudden change in supply of energy-yielding substrates from nutrients supplied in vivo via placental circulation to a milk diet high in lipid content. The idea that the appearance of dietary lipid has a specific role in modulating cellular metabolism during postnatal development has been difficult to test directly because of inherent problems in varying the neonatal diet of laboratory animals. The purpose of this study was to formulate one purified diet low in lipid for comparison with another equicaloric diet high in lipid. Ideally, both diets should be capable of supporting neonatal rabbits to at least 10 days of age. We accomplished the objective with lipid calories in the high fat (HF) diet balanced primarily against protein in the low fat (LF) diet. The HF and LF diets thus present a difference in protein content as well as lipid, which must be kept in mind for future applications of this experimental model. In this regard it is worth noting that others have found neonatal carcass composition remains constant over a wide range of variations in the amount of dietary protein $(8$, 
9). In rats, positive nitrogen balance was maintained with artificial diets supplying as little as one-tenth the normal milk protein fraction (8). This may reflect the low rate of protein synthesis during the first days of life (7).

The general pattern of physical development for HF and LF animals resembled that of mother-fed animals. There were interesting quantitative differences between the HF and LF groups. A detailed analysis of these observations is beyond the scope of the study, but they will be discussed briefly so as to provide information helpful to an evaluation of the suitability of the model for future developmental studies.

Pups fed the HF diet did not gain weight whereas littermates on the LF diet gained well. Lack of growth on the HF diet is probably not due to deficient intestinal absorption of the oils in the diet, since animals in that group showed large storage depots of fat at autopsy, particularly around the kidneys and in the brown adipose tissue. No organ-associated fat deposits were observed in LF animals, and brown adipose tissue was severely reduced in size. Liver homogenates (2) from HF animals were also very fatty as compared with those of LF animals. Nor can lack of growth simply be attributed to protein deficiency, since in a previous study (3) animals fed a "balanced" diet high in both lipid and protein did not gain weight. These results suggest that the relative proportion of lipid may influence the extent to which dietary protein is utilized for growth. Filer et al. (9) reported a similar effect of fat on protein metabolism in a dietary study of piglet development. If the proportion of fat in the diet was held constant ( $26.85 \%$ by weight), varying the protein fraction $(14-50 \%)$ had no effect on fat-free carcass composition. However, if dietary protein was held constant $(14 \%)$ while the fat fraction was varied $(2.5 \%$ vs. $26.85 \%)$, the protein content of both total carcass and liver was higher in the low fat group. These authors concluded the relative proportion of dietary fat may influence nitrogen or glycogen storage by the liver of piglets. In view of our results, this may also be the case for young rabbits. This possibility is even more likely if the BUN values are considered. BUN was similarly high in pups fed a "balanced" diet (3) and those fed the LF diet in the present study, suggesting that protein was metabolized effectively in both groups. Yet, only the LF group gained weight.

The gradual postnatal increase in body temperature with age is a complicated phenomenon, but probably reflects progressive maturation of mechanisms of chemical and physical thermoregulation and a concomitant adaptive increase in the hypothetical set point (10). Since lipid is usually the preferred substrate for chemical thermoregulation in neonates (10), the lower body temperatures observed in the HF animals are probably not caused by inadequate substrate supply. The difference in body temperature was apparent by day 3 . Body weights did not differ significantly until much later, so the difference in body temperature is probably not related to variations in surface/volume ratios or insulation. As noted previously, animals in group HF were observed to have extensive organ fat depots as compared with group LF, suggesting that insulation is probably greater in group HF. The lag in development of body temperature in the HF group as compared with the LF group is more likely related to differences in metabolic rate
(5). This is consistent with the idea (discussed above) that there is more efficient utilization of the LF diet.

A comparison of organ weights in the HF and LF groups was also of interest as a means of evaluating dietary regimens. Our finding of larger kidney and liver weights in the LF group is most likely due to the higher protein fraction in the LF diet. Filer et al. (9) found an increase in the liver and kidney weight as a function of increased dietary protein in piglets. The general effectiveness of high protein diets in increasing renal weight has been established for many years (11).

\section{SUMMARY}

We have shown that it is quite feasible to maintain neonatal rabbits away from the mother using purified artificial diets in which the amount of lipid can be varied to supply as little as $14.2 \%$ or as much as $77.6 \%$ of total calories. Some differences in physical development were observed as a function of diet. These differences were predictable consequences of the diet compositions. The neonatal model we have described provides an excellent opportunity for correlating these findings with biochemical studies of developing cell functions. In an accompanying paper (2) we report the results of an investigation comparing fatty acid oxidation in the HF and LF groups described here.

\section{REFERENCES AND NOTES}

1. Aas, M., and Daae, L. N.: Fatty acid activation and acyl transfer in organs from rats in different nutritional states. Biochim. Biophys. Acta, 239: 208 (1971).

2. Aprille, J. R.: Dietary lipid and postnatal development. Il. Palmitoyl coenzyme A oxidation in heart and liver. Pediat. Res., 10:982 (1976).

3. Aprille, J. R., and Rulfs, J.: A convenient neonatal model for developmental studies requiring artificial diets. Biol. Neonate (In press.)

4. Ballard, F. J., and Hanson, R. W.: Changes in lipid synthesis in rat liver during development. Biochem. J. 102: 952 (1967).

5. Cardasis, C. A., and Sinclair, J. C.: The effects of ambient temperature on the fasted newborn rabbit. Biol. Neonate, 21: 330 (1972).

6. Coates, M. E., Gregory, M. E., and Thompson, S. Y.: The composition of rabbits' milk. Brit. J. Nutr., 18: 583 (1964).

7. Czajka, D. M., Miller, S. A., and Browning, A. M.: Hepatic protein metabolism in the infant rat. J. Nutr., 100: 309 (1969).

8. Czajka-Narins, D. M., Miller, S. A., and Browning, A. M.: Studies of the protein requirement of the neonatal rat. J Nutr., 103: 1608 (1973).

9. Filer, L. E., Jr., Baur, L. S., and Pezabek, H.: Influence of protein and fat content of diet on the body composition of piglets. Pediatrics, 25: 242 (1960).

10. Heim, T.: Thermogenesis in the newborn infant. Clin. Obstet. Gynecol., 14: 790 (1971).

11. MacKay, E. M., and MacKay, L. L.: Factors which determine renal weight. VII. Protein intake and age. J. Nutr., 3: 375 (1931).

12. Smith, S., and Abraham, S.: Fatty acid synthesis in developing mouse liver. Arch. Biochem. Biophys., 136: 112 (1970).

13. Warshaw, J. B.: Cellular energy metabolism during fetal development. IV. Fatty acid oxidation during development of the chick and rat. Devop. Biol., 28: 57 (1972).

14. Warshaw, J. B., and Kimura, R. E.: Changes in hepatic microsomal fatty acid synthesis during development of the rat. Biol. Neonate, I22: 133 (1973).

15. CP 5332A, Ross Laboratories, Columbus, Ohio.

16. Nutritional Biochemical Co., Cleveland, Ohio.

17. This study was supported by grants from the United States Public Health Service (NIH HD08600) and the Charles H. Hood Foundation.

18. Requests for reprints should be addressed to: J. R. Aprille, Ph.D., Shriner's Burns Institute at the Massachusetts General Hospital, 50 Blossom St., Boston, Mass. 02114 (USA).

19. Accepted for publication June 4, 1976. 